\title{
Evaluation of Shear Peel Bond Strength of Different Adhesive Cements Used for Fixed Space Maintainer Cementation: An In Vitro Study
}

\author{
Jasmeet Kaur ${ }^{1}$, Amitoj Singh² ${ }^{2}$ Gunmeen Sadana ${ }^{3}$, Manjul Mehra ${ }^{4}$, Mamta Mahajan ${ }^{5}$
}

\begin{abstract}
Aim and objective: This study aims to compare the retentive strength of different adhesive cements used for band cementation of fixed space maintainer by comparing the shear peel bond strength and mode of failure for each adhesive material using three different adhesive cements. Materials and methods: Eighty intact extracted teeth were used to assess the shear peel bond strength. Preformed bands were adapted to each tooth. Three cements compared in this in vitro study are glass ionomer cement [Ketac Cem radiopaque (3M ESPE)], resin-modified glass ionomer cement [RelyX luting 2(3M ESPE)], and self-adhesive resin cement [RelyX U200 (3M ESPE)]. The teeth were randomly divided to four groups of 20 samples each. All samples were stored at $37^{\circ} \mathrm{C}$ for 24 hours before testing. All specimens were tested in a tensile mode using a universal testing machine to determine shear peel bond. After debonding procedure, each specimen was visually assessed at the site of cement. Results: The results of our study showed that the greatest resistance to decementation was shown by self-adhesive resin cement ( $256.85 \mathrm{~N})$ followed by resin-modified GIC $(165.40 \mathrm{~N})$ and GIC $(127.40 \mathrm{~N})(p<0.001)$. Self-adhesive resin cement has the greatest shear peel bond strength (2.36 MPa) followed by resin-modified GIC (1.53 MPa), conventional GIC (1.22 MPa), and bands without cementation ( $0.29 \mathrm{MPa})(p<0.001)$. In terms of adhesive remnant index (ARI) scores, it was seen that the decementation of bands of both conventional GIC and self-adhesive resin cements occurred at the band/enamel interface. However, resin-modified GIC showed varied results in the ARI scores.

Conclusion: The findings of our study suggest that self-adhesive resin cements can be used for cementation of bands of fixed space maintainers. However, further research with short-term and long-term data is required to evaluate the ability of these cements for its application in vivo.

Keywords: Band, Prefabricated bands, Shear bond strength, Shear peel bond strength, Space maintainer.

International Journal of Clinical Pediatric Dentistry (2021): 10.5005/jp-journals-10005-1932
\end{abstract}

\section{INTRODUCTION}

Deciduous dentition plays a crucial role in the growth and development of children. It helps not solely in chewing, however, additionally aids in speech, esthetics, prevention of onset of oral habits, and also guides the permanent teeth in the dental arch. ${ }^{1}$ When the physiological process of shedding of primary teeth and eruption of permanent teeth is halted because of premature loss of primary teeth it may result in issues like reduction of arch space, blocked or deflected eruption of permanent teeth. The best way to prevent such problems is to preserve the deciduous teeth in the arch till they shed at their normal time as deciduous teeth serve as the best space maintainer. In several cases, extraction or loss of tooth is inevitable then the best possible option to maintain the arch space is by placing a space maintainer. ${ }^{2,3}$

Space maintainers may be removable, semi-fixed or fixed, banded or non-banded, functional or non-functional, active or passive; of which fixed appliances are the foremost advantageous. Steel band-supported space maintainers are the most commonly used. ${ }^{4,5}$

Retention of the band depends on its close adaptation to the tooth by cement lute. Numerous studies done antecedently have shown advances in the area of dental cements with the event of the latest varieties. ${ }^{6}$ Many studies within the past have investigated the chemical composition of varied cements, their physical and chemical properties, and their application as well as use in restorative dentistry. Earlier, zinc phosphate cements were widely used for luting bands but have limitations of high solubility and relying entirely on mechanical adhesion for their retention.
${ }^{1,3,4}$ Department of Pedodontics, Sri Guru Ram Das Institute of Dental Sciences and Research, Amritsar, Punjab, India

2,5Department of Prosthodontics, Himachal Dental College, Sundar Nagar, Himachal Pradesh, India

Corresponding Author: Jasmeet Kaur, Department of Pedodontics, Sri Guru Ram Das Institute of Dental Sciences and Research, Amritsar, Punjab, India, Phone: +91 9988299064, e-mail: docjasmeetkaur@ gmail.com

How to cite this article: Kaur J, Singh A, Sadana G, et al. Evaluation of Shear Peel Bond Strength of Different Adhesive Cements Used for Fixed Space Maintainer Cementation: An In Vitro Study. Int J Clin Pediatr Dent 2021;14(2):175-179.

Source of support: Nil

Conflict of interest: None

Other dental cements have been developed to overcome these shortcomings. Polycarboxylate cements react chemically with enamel and stainless steel. Its disadvantages like high viscosity, short setting time, and high intraoral solubility decreased its use as luting cement. ${ }^{7}$

Glass ionomer cements have been very popular for the cementation of fixed space maintainers. ${ }^{5}$ Relative to zinc phosphate it has lower solubility in saliva, higher tensile and compressive strengths, and also form ionic bonds with stainless steel. ${ }^{7}$ The key disadvantage of this cement is its sensitivity to moisture during its setting, and maximum bond strength being reached after 24 hours. ${ }^{5,8}$ 
New advancement in GIC technology occurred with the use of glass ionomer hybrid materials, resin-modified glass ionomers (RMGI), their favorable properties like low solubility, ability to chelate via acid-base reaction to enamel and metal, moisture tolerance, good tensile, and compressive strength confers it superior to the GICs. The only limitation of this cement is its questionable fluoride release. ${ }^{5,9}$ The most recent resin cements, selfadhesive resin cements were introduced in 2002. These cements mix the advantages of adhesive and conventional luting agents and were designed to overcome the drawbacks of both traditional and resin cements. Adhesion occurs by micromechanical retention and chemical retention between monomer acidic groups and hydroxyapatite. $^{10}$

A review of the literature reveals that the foremost frequent site of failure of bands is at the band-cement interface. Hence, it warrants further investigation on methods to reinforce bond strength at the metal-cement interface to improve retention. Increasing the bond strength at this interface should reduce the risk of band loosening. The purpose of this study was to assess the shear peel bond strength of bands of fixed space maintainer cemented using three different luting cements and to assess the site of bond failure.

\section{Materials and Methods}

For this study, 80 sound extracted molars were taken supporting the following:

\section{Inclusion Criteria}

- Intact enamel.

- Absence of any crack because of extraction forceps or otherwise.

- Non-carious.

- No previous restoration.

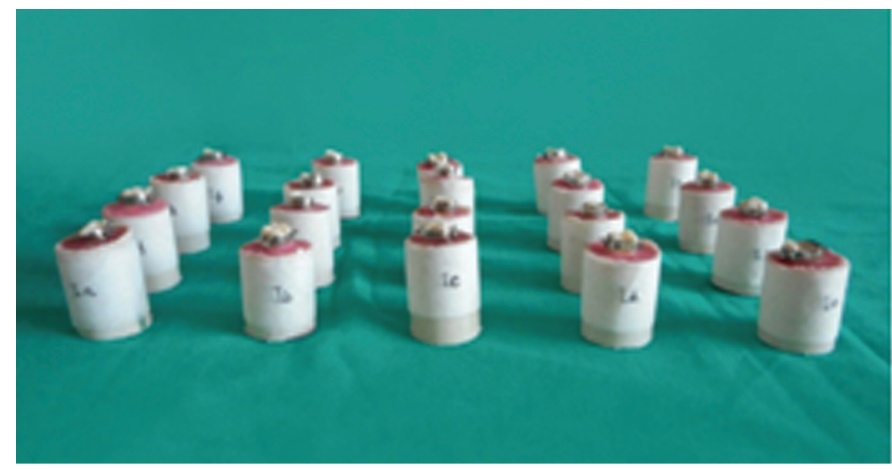

Group I

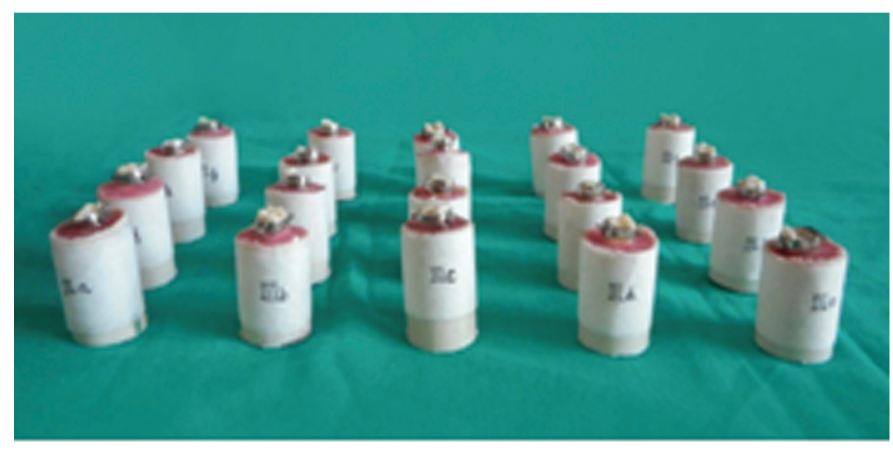

Group III

\section{Exclusion Criteria}

- Previously restored molars.

- Presence of enamel defect.

- Presence of any crack because of extraction forceps.

- Carious tooth.

Each tooth was mounted with auto-polymerizing resin in polyvinyl chloride sleeves to the level of cement-enamel junction. The acrylic blocks were number-coded with different numbers for each group. The band was adapted to the best fit for each tooth. Two opposing orthodontic begs brackets were spot welded on preformed bands and then adapted onto the tooth. Subsequently, the teeth were divided randomly into 4 groups ( 20 each): group I (control group), in which bands were adapted without cementation; group II, in which bands were cemented via conventional GIC (Ketac Cem radiopaque, 3M ESPE); group III, in which bands were cemented using RMGIC (Rely X Luting 2, 3M ESPE); and group IV, in which bands were cemented using self-adhesive resin cement (Rely X U200, 3M ESPE) (Fig. 1).

Manufacturer's instructions were followed for cementation of bands in each group. After waiting for 10 minutes, the samples were stored at $37^{\circ} \mathrm{C}$ and humid environment for 24 hours in hot air oven. The bond strength was tested within 24 hours at Central Institute of Plastics Engineering and Technology, Amritsar using INSTRON Universal testing machine at a cross head speed of $1 \mathrm{~mm} /$ minute in tensile mode. The mounted teeth were clamped to the attachment equipment of the INSTRON (Fig. 2). The orthodontic bands were attached with $0.3 \mathrm{~mm}\left(0.010^{\prime \prime}\right) \mathrm{SS}$ wire loops which were engaged in the buccal tubes of each band. A custom-made jig was clamped to the attachment apparatus of the INSTRON superiorly to engage the stainless steel wire loops. Testing was done for each sample till the band was aloof from the tooth; the utmost force required
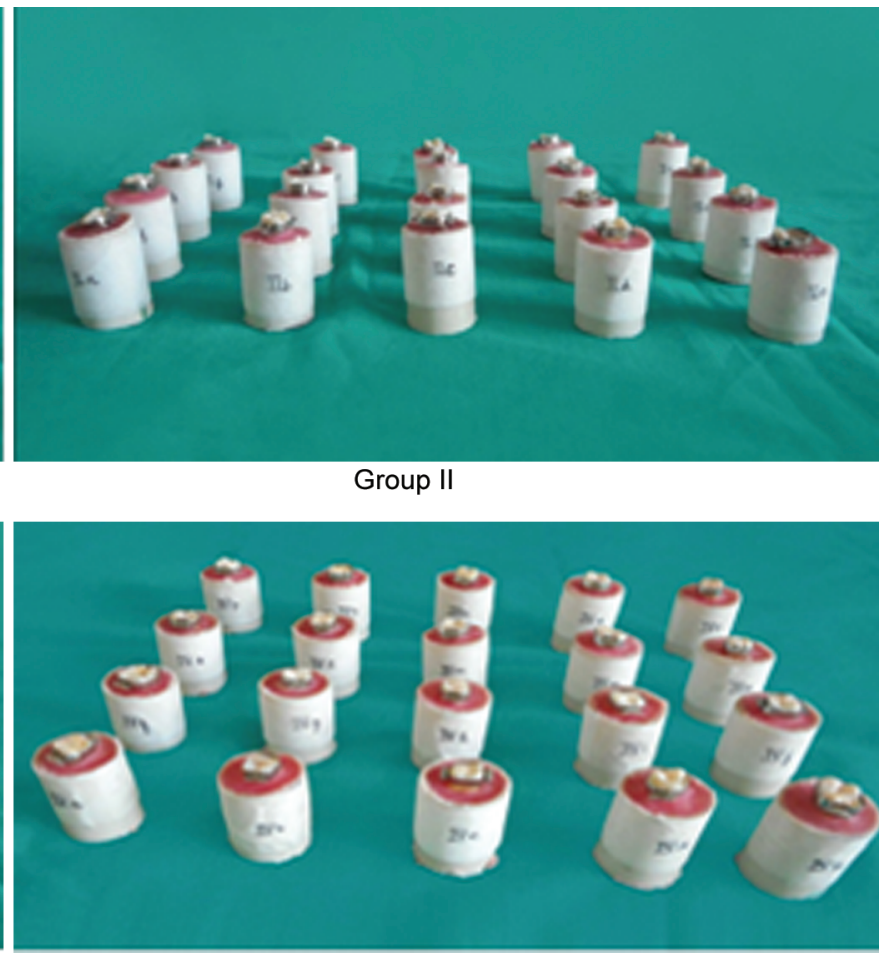

Group IV

Fig. 1: Samples after dividing randomly into four groups 


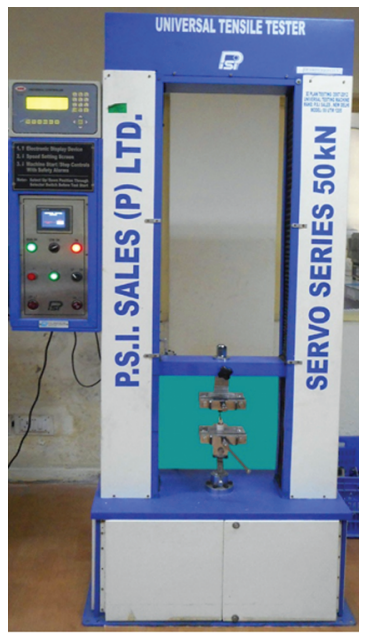

Fig. 2: Universal testing machine

to remove the band was recorded for every specimen and was measured in Newtons.

After the debonding procedure, adhesive remnant index (ARI) index grading was done as follows:

0 -No cement present on the tooth surface.

$1-<1 / 2$ of the tooth surface covered by cement.

$2 \rightarrow 1 / 2$ of the tooth surface covered by cement.

3-All of the tooth surface under the band covered by cement.

Once the tooth was removed from the attachment equipment, the loop was removed from the band and the band was cut and its length and breadth were measured to the closest with a digital Vernier caliper and thus the area was determined in $\mathrm{mm}^{2}$. Shear peel bond strength was calculated by:

\section{Shear peel band strength (in Megapascal)}

$=$ Force (inNewtons) / Surface area of band (in millimeter ${ }^{2}$ )

The data collected were analyzed using Statistical Package for Social Sciences (SPSS) version 17 (SPSS Inc., California, USA).

Descriptive data were presented in the form of frequencies, percentages, mean and standard deviation. One-way analysis of variance (ANOVA) was used to compare mean bond strengths, the maximum load, and the surface area of the evaluated cements. Pairwise comparison of the study variables namely, maximum load (in Newtons), mean bond strengths between the study groups was done using Tukey's post hoc test. Chi-square analysis was done to compare the ARI scores to assess the predominant site of cement failure.

\section{Results}

All the groups showed statistically significant differences in shear peel bond strength values when compared to each other ( $p<$ $0.001)$. The retention value of self-adhesive resin cement was highest followed by RMGIC, GIC, and group I (Table 1). Most of the samples showed adhesive failure at the band-cement interface. Significant difference was found between the four cements with regard to the site of failure which was visually assessed and classified by ARI. The values from the ARI were subjected to Chi-square analysis to assess the predominant site of cement failure $(p<0.05)$. In group II (conventional GIC), the maximum frequency for ARI score 1 ( $n=17$, $85 \%$ ) followed by score 0 ( $n=3,15 \%)$. In group III (RMGIC), maximum frequency was seen for score $1(n=12,60 \%)$ followed by score 2 ( $n$ $=6,30 \%$ ) and score $0(n=2,10 \%)$. In group IV (self-adhesive resin cement), maximum frequency was seen for score $1(n=18,90 \%)$ followed by score 0 and 1 ( $n=1,5 \%$ ) (Table 2).

\section{Discussion}

Previous studies have discussed indications, contraindications, and considerations for various space maintainers. Of all the space maintainers, band-supported space maintainers are most commonly used. Glass ionomer cements are widely used for band cementation because of its fluoride releasing property and its ability and to both enamel and metal. However, these cements have not excluded the problem of the failure of attachment of the stainless steel band to the tooth. Fathian et al. observed in their study that cement loss account for over $70 \%$ of band and loop appliance's failures using Ketac cement. Also, Sasa et al. using Ketac Cem reported failure rate of banded space maintainers due to cement loss to be $82 \% .^{11}$

Table 1: Comparison of the mean values of shear peel bond strength using ANOVA

\begin{tabular}{llllll}
\hline Group & $N$ & Mean shear peel bond strength $(\mathrm{MPa})$ & Range & Fvalue & $p$ value \\
\hline I & 20 & $0.29 \pm 0.04$ & $0.19-0.38$ & 205.22 & $<0.001^{* * *}$ \\
II & 20 & $1.22 \pm 0.24$ & $0.71-1.81$ & & \\
III & 20 & $1.53 \pm 0.28$ & $1.13-2.36$ & & \\
IV & 20 & $2.36 \pm 0.37$ & $1.71-2.86$ & & \\
\hline
\end{tabular}

$p<0.001^{* *}=$ statistically significant

Table 2: Comparison of the site of failure between the study groups using Chi-square value analysis

\begin{tabular}{lllrrr}
\hline & \multicolumn{5}{c}{ Group } \\
\cline { 2 - 6 } ARI score & $I$ & \multicolumn{1}{l}{ II } & \multicolumn{1}{c}{ III } & $2(10 \%)$ & 7 \\
\hline 0 & - & $3(15 \%)$ & $12(10 \%)$ & $16(80 \%)$ & 45 \\
1 & - & $17(85 \%)$ & $12(60 \%)$ & $2(10 \%)$ & 8 \\
2 & - & - & $6(30 \%)$ & - & - \\
3 & - & - & - & 20 & 60 \\
Total & - & 20 & 20 & & \\
\hline
\end{tabular}

Chi-square value $(\mathrm{df})=8.219, p=0.084$; Not significant

However, II vs III significant, II vs IV and III vs IV not significant 
According to earlier clinical studies, long-term failure rates of band and loop space maintainers ranged from 29 to $59 \%$ at periods of 9-14 months following application. Previous research reveals that improper fit or faulty cementation of a band to the tooth can accommodate accumulation of dental plaque and result in enamel decalcification..$^{12}$ Additionally, poor cementation can lead to losening of the band and thereby reducing its effectiveness. Verifying and observing mechanical properties of different dental materials may ascertain which material is apt to perform in clinical functions and resist masticatory forces and wear. ${ }^{13}$

In this study, the greatest resistance to decementation was shown by self-adhesive resin cement which showed a mean value of $256.85 \mathrm{~N}$ followed by RMGIC and GIC which showed a mean value of 165.40 and $127.40 \mathrm{~N}$, respectively. The least resistance to decementation was shown by the control group (bands without cementation) which showed a mean value of $30.30 \mathrm{~N}$. The findings of our study were highly significant statistically $(p<0.001)$. Intergroup comparison for greatest resistance to decementation showed that group I (control group) when compared to group II (conventional $\mathrm{GIC}$ ) had significantly lower mean value of $97.10 \mathrm{~N}(p<0.001)$. On comparison of group I with group III (RMGIC) and group IV (selfadhesive resin cement), it was found that group I had significantly lower mean value of 135.10 and $226.55 \mathrm{~N}$, respectively $(p<0.001)$. Group II (conventional GIC) in comparison to group III (RMGIC) and group IV (self-adhesive resin) showed a significantly lower mean value of 38 and $129.45 \mathrm{~N}$, respectively $(p<0.001)$. Group III (RMGIC) when compared to group IV (self-adhesive resin) showed a significantly lower mean value of $91.45 \mathrm{~N}(p<0.001)$.

We assessed the shear peel bond strength of different luting cements in our study which can be summarized as follows; selfadhesive resin cement has the greatest bond strength which showed a mean value of $2.36 \mathrm{MPa}$ followed by RMGIC, conventional $\mathrm{GIC}$, and bands without cementation which showed a mean value of $1.53,1.22$, and $0.29 \mathrm{MPa}$, respectively $(p<0.001)$.

Intergroup comparisons showed that the shear peel bond strength of bands in group I (without cementation) in comparison to groups II, III, and IV was significantly lower by a mean value of $0.93,1.24$, and $2.06 \mathrm{MPa}$, respectively. Group II showed a significantly lower mean value in comparison to group III and IV $(p<0.001)$. Group III in comparison to group IV showed a significantly lower mean value of $0.82 \mathrm{~N}(p<0.001)$

The values of variables under study were highly significant statistically $(p<0.001)$. The findings of the present study showed that self-adhesive resin cement has better retentive strength than RMGIC followed by conventional GIC. The results are in congruence to the earlier research done by Prabhakar et al. who reported that the mean retentive strength was highest with resin cement followed by RMGIC, GIC, and bands without cementation, respectively. In accordance to the results of the present study, Compton et al. reported a higher shear bond strength of light cured GIC than chemically cured GIC. ${ }^{14}$ Millett et al. reported higher bond strength of dual cured resin cement when compared to conventional GIC (Ketac Cem).

Self-adhesive resin has not been used for luting bands. However, studies are done previously to compare the shear bond strength of brackets bonded using self-adhesive cements. ${ }^{15}$

It is noticeable that the greater retention shown by self-adhesive resin cement is due to micromechanical retention and chemical retention between monomeric acidic groups and hydroxyapatite.
Its multifunctional monomers with phosphoric acid groups concurrently demineralize and infiltrate enamel and dentin. The predominant setting reaction is the radical polymerization that can be started by light exposure or through the linking of cement monomers and the creation of high molecular weight polymers. RMGICs are notably superior to conventional GICs in mechanical properties. This is likely due to the ability of 2-HEMA to balance the network flexibility after the curing of methacrylate groups bonded to polycarboxylate chains.

In our study, we found that RMGIC presented higher shear peel bond strength when compared to conventional GICs. On the contrary, previous studies done found that conventional GICs did not significantly differ from RMGICs. Catekin et al. concluded in their study that conventional GICs presented higher bond strength than resin-based cements for space maintainer cemented bands. The difference of results of our study are due to various factors such as different debonding location evaluation scale, customized band removal device, cross head speed.

In the present study, bond failure occurred considerably at the enamel-cement interface. Adhesive remnant index differed significantly among the groups $(p<0.05)$.

\section{Conclusion}

- The highest values in terms of the maximum load were shown by self-adhesive resin cements (RelyX U200) followed by resinmodified GIC (RelyX luting 2) and lowest for conventional GIC (Ketac Cem).

- The highest shear peel bond strength was reported for self-adhesive resin cement (RelyX U200) followed by resinmodified glass ionomer cement (RelyX luting 2) and lowest for conventional glass ionomer cement (Ketac Cem).

- As per the ARI scores recorded in our study, both conventional GIC and self-adhesive resin cement showed cement failure at the cement/enamel interface. The resin-modified glass ionomer (RMGIC), however, showed variable failure sites.

- This study suggests that the self-adhesive resin cement can be considered for cementation of bands for a fixed space maintainer.

\section{References}

1. Barberia E, Lucavechi T, Cardenas D, et al. Free-end space maintainers: design, utilization and advantage. J Clin Pediatr Dent 2006;31(1):5-8. DOI: 10.17796/jcpd.31.1.p87112173240x80m.

2. Setia V, Pandit IK, Srivastava N, et al. Space maintainers in dentistry: past to present. J Clin Diagn Res 2013;7(10):2402-2405. DOI: 10.7860/ JCDR/2013/6604.3539.

3. Laing $E$, Ashley $P$, Naini FB, et al. Space maintenance. Int J Paediatr Dent 2009;19(3):155-162. DOI: 10.1111/j.1365-263X.2008.00951.x.

4. Garg A, Samadi F, Jaiswal JN, et al. 'Metal to resin': a comparative evaluation of conventional band and loop space maintainer with the fiber reinforced composite resin space maintainer in children. J Indian Soc Pedod Prev Dent 2014;32(2):111-116. DOI: 10.4103/09704388.130783.

5. Prabhakar AR, Mahantesh T, Ahuja V. Comparison of retention and demineralization inhibition potential of adhesive banding cements in primaryteeth. J Dent Child 2010;77(2):66-71.

6. Uysal T, Ramoglu SI, Ertas H, et al. Microleakage of orthodontic band cement at the cement-enamel and cement-band interfaces. Am J Orthod Dentofacial Orthop 2010;137(4):534-539. DOI: 10.1016/j. ajodo.2008.03.025. 
7. Millett DT, Duff S, Morrison L, et al. In vitro comparison of orthodontic band cements. Am J Orthod Dentofacial Orthop 2003;123(1):15-20. DOI: $10.1067 /$ mod.2003.48.

8. Cantekin K, Delikan E, Cetin S. In vitro bond strength and fatigue stress test evaluation of different adhesive cements used for fixed space maintainer cementation. Eur J Dent 2014;8(3):314-319. DOI: 10.4103/1305-7456.137632.

9. Aggarwal M, Foley TF, Rix D. A comparison of shear peel band strengths of 5 orthodontic cements. Angle Orthod 2000;70(4):308316. DOI: 10.1043/0003-3219(2000)0702.0.CO;2.

10. Radovic I, Monticelli F, Goracci C, et al. Self-adhesive resin cements: a literature review. J Adhes Dent 2008;10(4):251-258.

11. Sasa IS, Hasan AA, Qudeimat MA. Longevity of band and loop space maintainers using glass ionomer cement: a prospective study. Eur Arch Paediatr Dent 2009;10(1):6-10. DOI: 10.1007/BF03262659.
12. Killian CM. Cementation of a fixed orthodontic appliance. Quintessence Int 1991;22(7):547-550.

13. Millett DT, Kamahli K, McColl J. Comparative laboratory investigation of dual-cured vs. Conventional glass ionomer cements for band cementation. Angle Orthod 1998;68(4):345-350. DOI: 10.1043/00033219(1998)0682.3.CO;2.

14. Compton AM, Meyers CE, Hondrum SO, et al. Comparison of the shear bond strength of a light cured glass ionomer and a chemically cured glass ionomer for use as an orthodontic bonding agent. Am J Orthod Dentofacial Orthop 1992;101(2):138-144. DOI: 10.1016/08895406(92)70005-U.

15. Al-Saleh M, El-Mowafy O. Bond strength of orthodontic bracket with new self-adhesive resin cements. Am J Orthod Dentofacial Orthop 2010;137(4):528-533. DOI: 10.1016/j.ajodo.2008.04.027. 